\title{
Solar Powered Automated Irrigation System with Plant Health Indication Using IoT
}

\author{
P. Ramya, T.R. Annapoorneswari, G.V. Bindu, \\ N.V. Meghana, U. Roshni
}

\begin{abstract}
Horticulture is a field where robots are not given a significant importance. Since we are mainly concentrating on medicinal plant they require high care. In this field, the demand for robots and automated systems are increasing hence in the course of this paper we made an attempt to scale down human labor by creating an automation which is able to indicate plant health. The aim of this paper is creating a farming automation which is able to indicate the plant health by observing color of their leaves and to provide the automated irrigation system. The automation will note encompassing environmental conditions like temperature, soil moisture and $\mathrm{pH}$ it will be displayed in order that automation can decide health of the plant particular pesticides will be sprayed and the entire project is powered by solar using MPPT.
\end{abstract}

Keywords--- Solar Energy, Automated Irrigation System, Image Processing, Arduino, Medicinal Plants, Maximum Power Point Tracking (MPPT).

\section{INTRODUCTION}

India has powerful historic health care practices which is portrayed by the classical systems of medicine like Ayurveda, Siddha, Unani, and Swa-rigpa. Majority of the Indian health care traditions depends on raw materials extracted from the huge range of plant species which is approximately 6,500. In order to estimate the present demand and supply of medicinal plants, National Medicinal Plant Board (NMPB) made a survey on a herbal market of India. The estimated commercial demand of herbal raw drugs in the year 2014-2015 was approximately 5,12,000 MT. exports of herbal raw drugs was estimated 1,34,500 MT in the year 2014-2015.the consumption by domestic herbal industry has been estimated 1,95,000 MT 20142015.rural household uses 1,67,500 MT of herbal raw drugs every year. But the demand for medicinal plants is accompanied by decreasing the supply of these plants which is due to overexploitation, habitat destruction. Medicinal plants are also known as medicinal herbs. The world health organization estimates that around $80 \%$ of the world's population use herbal medicines and natural remedies for primary health care needs. There are 1000 of plants through the world that have medicinal uses many of them are also used in medicine to make pharmaceutical drugs.

Cultivating medicinal plant requires high care in modern trends, different irrigation methods are used to reduce the dependency of rain and mostly the existing irrigation system

Manuscript received September 16, 2019.

P. Ramya, Assistant Professor, Electrical and Electronic Department, Sri Venkateshwara College of Engineering, Bangalore, India.

T.R. Annapoorneswari, Electrical and Electronic Engineering, Sri Venkateshwara College of Engineering, Bangalore, India.

G.V. Bindu, Electrical and Electronic Engineering, Sri Venkateshwara College of Engineering, Bangalore, India.

N.V. Meghana, Electrical and Electronic Engineering, Sri Venkateshwara College of Engineering, Bangalore, India.

U. Roshni, Electrical and Electronic Engineering, Sri Venkateshwara College of Engineering, Bangalore, India. are driven by electrical power. The manual controlled irrigation systems cannot ensure a proper level of water in the sites. Due to the lack of electricity and mismanagement in the manually controlling system, sometimes their fields become dry and sometimes flooded with excess water this may cause water wastage. There is an urgent need to create strategies based on science and technology for sustainable use of water, detect the present condition in medicinal plant. Below table shows some of the diseases and respective remedies with appearance.

Table 1: Diseases and Respective Remedies with Appearance

\begin{tabular}{|c|c|c|}
\hline Diseases & Appearance of leaves & Remedies \\
\hline $\begin{array}{l}\text { Early } \\
\text { bright }\end{array}$ & $\begin{array}{l}\text { Brown spots with } \\
\text { concentric rings on leaves. }\end{array}$ & Neem oil. \\
\hline $\begin{array}{l}\text { Power } \\
\text { mildew }\end{array}$ & $\begin{array}{l}\text { Powdery white spots on } \\
\text { leaves. }\end{array}$ & $\begin{array}{l}\text { Potassium } \\
\text { bicarbonate. }\end{array}$ \\
\hline $\begin{array}{l}\text { Septoria } \\
\text { leaf spot }\end{array}$ & $\begin{array}{l}1^{\text {st }} \text { yellow or water socked } \\
\text { spots on leaves then turns to } \\
\text { black spots. }\end{array}$ & $\begin{array}{l}\text { Copper } \\
\text { sulphate. }\end{array}$ \\
\hline $\begin{array}{l}\text { Spider } \\
\text { mites }\end{array}$ & Yellowing of leaves. & Soup spraying \\
\hline
\end{tabular}

mites

This system is usually designed for ensuring the proper level of water for growing up the plants throughout the season even when the person who looks after it is away. These automatic irrigation systems always ensure the proper level of water in the sites. In order to achieve automatic irrigation system we have used many sensors such as temperature, soil moisture, $\mathrm{pH}$ sensor, IR sensor that sense the respective parameters and send the signal to the arduino which will automatically turns on or off the motor to water the plants based on environmental conditional .Since this proposed paper mainly concentrate on plant health by gathering the biological conditions like chlorophyll, pigmentation levels a technique of image processing is used. A robot is used for this purpose in which web camera is placed so that it will capture the images of the plant .This entire system is powered with solar and battery .Since solar is renewable source of energy which will overcome the drawbacks of mismanagement, lack of energy and interrupted power supply from electrical company

\section{LITERATURE SURVEY}

"Plant Disease Detection Using Raspberry PI By Kmeans Clustering Algorithm" [Priyanka G. Shinde, Ajay K. Shinde, Ajinkya A. Shinde, Borate S. P].The proposed solution involves. 
Examination of diseased and healthy leaves is one of the major Difficulties faced in horticulture production. The leaf miner larvae live inside of the leaves, feeding on the soft, inner plant tissue found between the upper and lower sides of the leaf. As they eat along the infested leaves, mining pattern of zigzag lines on the leaves are produced. Although leaf miners rarely kill or seriously injure a plant, it will give an unpleasant appearance and hence their control of elimination is important. In addition, they can destructive to young plants and seeding's, if infested. If plant is infested too much, it can end up in leaf drying or plant drying. Pesticides should be sprayed at the right time, so that they will reach the leaf miner larva and kill the leaf, inner flies. Hence we can detect the disease by a technique called image processing and can feed the pesticides automatically without human interference [1].

"Autonomous Plant Health Indication System Using Image Processing In MATLAB" [Prof.MeenakshiSaron, AjinkyaBorse, Rohan Parsekar, VinitHarsora, Pratik Shirsekar]. This project focused on vision based automatic irrigation system. Designed a unique system for plant and food research that makes use of a number of engineering theories of electrical and computer systems. With the help of different sensors like proximity, temperature, color and humidity system designed an automatic irrigation process. System will indicate the plant health using PC using MathLab and if the condition is not normal sends SMS [2].

"Android based Solar Powered Automatic Irrigation System" [Ashutosh Gupta, Varun Krishna, Saarthak Gupta and Jitesh Aggarwal]. The proposed system intimate faithful irrigation system using solar energy. Internet of Things (IOT) has been incorporated into the system for automatic monitoring and control, also takes care of the range issue and furthermore reduces the expanse of messages. Here solar power has utilized for controlling the system. To get continues power solar tracers are used [3].

"Solar Powered Sensor Base Irrigation System" [KavitaBhole, Dimple Chaudhari].Because of absence of power and mismanagement, crops are often dry or flooded with water in manual system. Therefore, to avoid this problem proposed system is used. In the manual system, humans usually control electric motors to pump water for soil and weather condition by visiting the field. To get continues power solar tracers are used. The purpose of using solar tracking system is to get maximum sun light. Solar panels are moved according to movement of sun's movement and movement of panels are done using DC motors. Light Dependent Resister (LDR) used to detect the sunlight and data sent to controller accordingly. Solar panels are controlled through a controller using LDR [4].

\section{PROBLEM STATEMENT}

The present problem faced in the field of horticulture is that the manual detection of the condition of the plant gives very inaccurate results. The human eye cannot manually detect what amount of water is required for irrigation. If the water supplied to the plant is too less then plant may dry and if the water supplied is too excess then plant may decay. We manuallyalso cannot detect what kind of bacteria, fungi or virus is affecting the plant health and hence we cannot estimate what measures are required to be taken. This results in poor quality and quantity of the plants during the time of harvesting. Hence we are using an automatic system our proposed paper to overcome these major problems faced in the field of horticulture.

\section{OBJECTIVES}

- The main objective of our proposed paper is to provide an automated Irrigation system, entirely powered by solar energy.

- This paper also mainly concentrates on plant health indication with the help of various sensors and a technique known as Image Processing.

- Water is supplied to plants based on temperature of the surroundings, $\mathrm{pH}$ levels and moisture content present in the soil.

- It identifies type of disease affecting the plant and sprays the suitable pesticide to the plant.

\section{METHEDOLOGY}

The Figure 1 shows the block diagram of the proposed paper. The entire system is powered using solar energy in order to make maximum utilization of solar energy. Solar panels are equipped with Maximum Power Point Tracking (MPPT),it uses electronics so that PV cells functions to produce the maximum quantity of power possible. It is not a mechanical tracking; it works on electronics to ensure optimum tracking and therefore optimum performance followed by maximum output. It always ensures that the panel is facing in the direction of sun and thereby operates the panels at peak power for longer period of time in a day. They adopt sun seeking sensors to locate the position of sun and move the array accordingly using motors and gears. The energy produced can be stored in storage devices like battery.

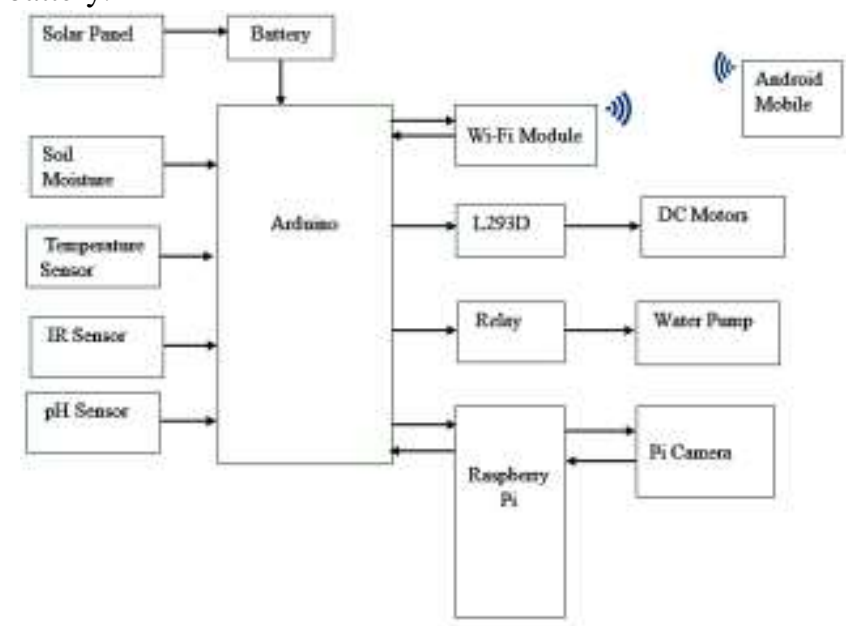

Fig.1: Block diagram

The entire system can be divided into two different blocks like irrigation part and the image processing part. The entire components are mounted on the robot. 


\section{Irrigation Part}

In order to monitor the condition of the environment various sensors like IR sensor, $\mathrm{pH}$ sensor, Temperature sensor and soil moisture sensors are used. The name of these sensors justifies their operation. These sensors sense the parameters and sends the values to the Arduino.

The readings obtained are tabulated as

Table 2: Readings of Various Sensors

\begin{tabular}{|l|c|c|c|c|}
\hline $\begin{array}{c}\text { Type of } \\
\text { the plant }\end{array}$ & $\begin{array}{c}\mathrm{pH} \\
\text { sensor }\end{array}$ & $\begin{array}{c}\text { IR } \\
\text { sensor }\end{array}$ & $\begin{array}{c}\text { Temperature } \\
\text { sensor }\end{array}$ & $\begin{array}{c}\text { Soil } \\
\text { moisture } \\
\text { sensor }\end{array}$ \\
\hline Healthy & 37 & 1 & 29.93 & DRY \\
\hline Healthy & 49 & 1 & 29.45 & DRY \\
\hline Healthy & 11 & 1 & 29.93 & NORMAL \\
\hline Healthy & 9 & 1 & 29.45 & NORMAL \\
\hline
\end{tabular}

\section{Image Processing Part}

The image processing part uses Raspberry $\mathrm{Pi}$ and the $\mathrm{Pi}$ camera. The pi camera will give input to the raspberry pi for image processing with the help of image processing we are identifying the fault condition if present any. The output of that will be further transferred to the microcontroller through UART. If the condition is not normal then the motor is turned $\mathrm{ON}$ and the pump is ON due to the relay action.

The interfacing between the Arduino and the raspberry Pi is done in such a way that, when the robot senses a pot in front of it the IR sensor goes high and the robot stops. Immediately the Pi camera operates and takes the picture of the plants and compares it with the RGB standards. If the plant detected by it is green then it sprays only water, but if the plant detected by it is yellow it sprays both pesticide as well as water. The Pi camera is also able to detect the black spots on the leaf. Now this leaf is considered to be unhealthy and the robot sprays the water and required pesticides.

For our case study we have conducted this experiment on Tulsi, the holy basil plant. This plant is mostly known for its medicinal and is been used as a traditional medicine. Around the quarter of drugs that are prescribed to patients are these traditional medicines.

The results obtained from the image processing using raspberry $\mathrm{Pi}$ for normal healthy, un-healthy, plant having black spots and yellow leaves are shown below

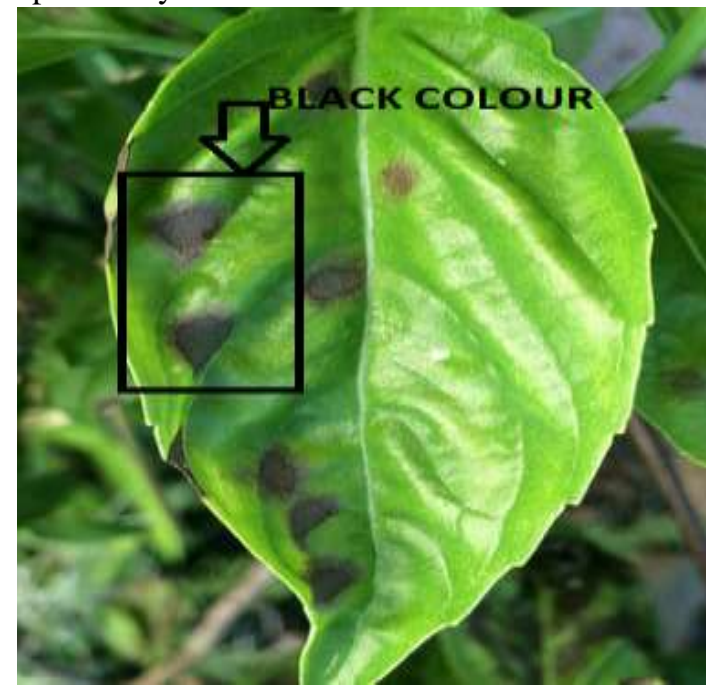

Figure 2: Captured Images of infected leaf
This above figure obtained from the raspberry Pi shows that the plant contains some black spots that can be seen by a black box. In this situation the plant is considered to be unhealthy and the robot sprays both the water and pesticides.

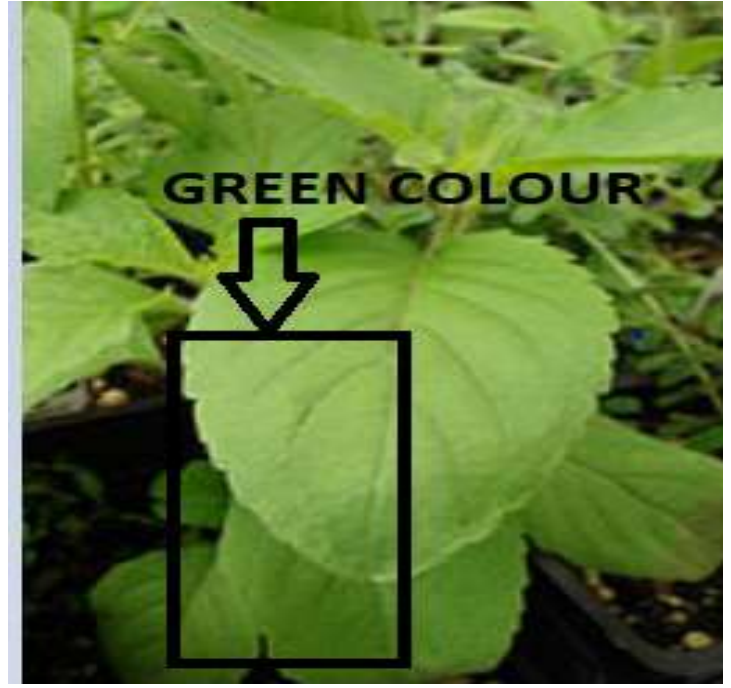

Figure 3: Captured Image of Healthy basil plant

This above figure captured by the $\mathrm{Pi}$ camera is of a healthy holy basil plant. In this case the healthy plant is monitored for the values obtained from the arduino and depending on these values the robot decides whether it can spray the water or not.

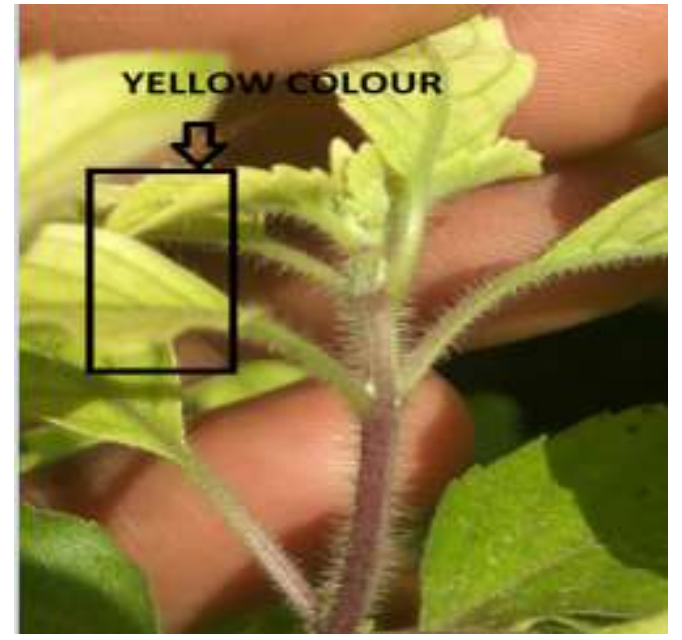

Figure 4: Captured Image of Basil With Yellow Leaves

This image captured by the Pi camera shows that the holy basil (Tulasi) has some yellow leaves. This indicates that the values obtained on the app are not nominal values and the plant has to be supplied by both water and respective pesticides.

These values can be seen on the Blynk android application via Wi-Fi module. Thus the greatest advantage of this project is that the person who looks after it need not to be around it always and he also gets information about what's going on his field.

Here are a few readings that we got from the Blynk app when the soil condition was dry and normal. When the soil is dry, the $\mathrm{pH}$ sensor shows some garbage values since there is no moisture content in the soil. 


\section{Flow Chart}

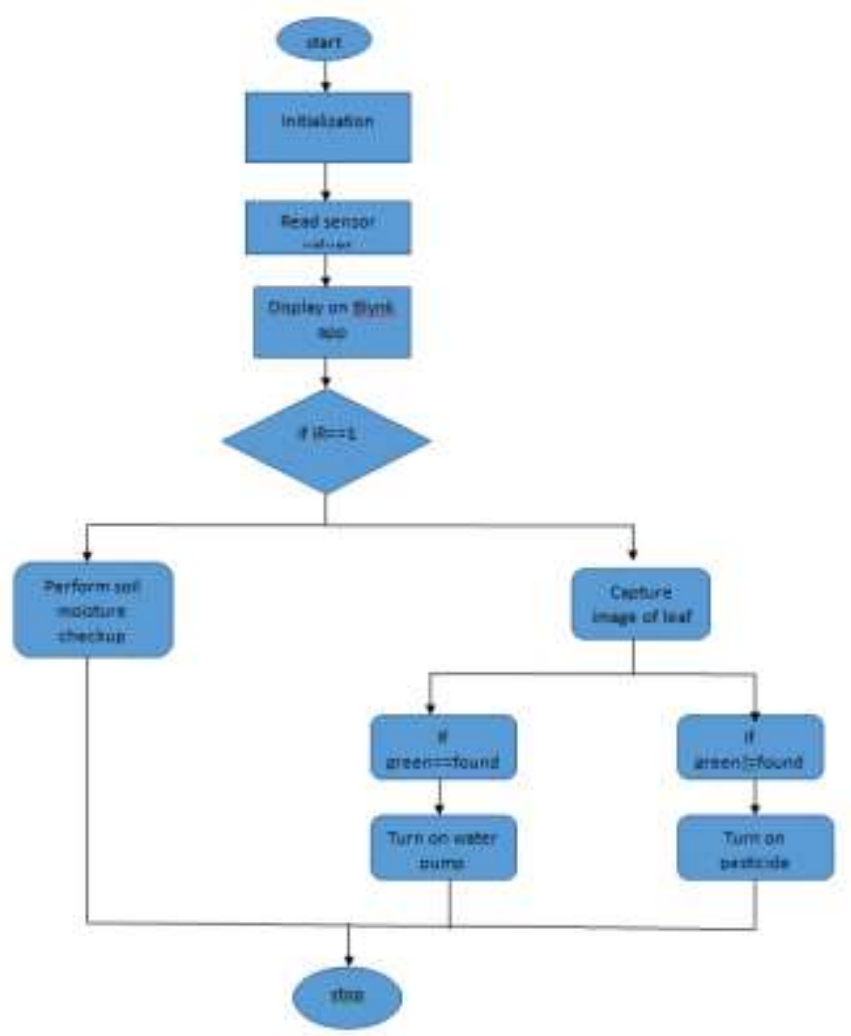

Fig. 6: Flowchart of the entire proposed system

\section{$B L Y N K A P P$}

It is an open source app for android and iOS that helps us to connect to cloud. It is an IoT for the Arduino. After downloading the app, create an account and enter the auth token sent to the mail ID. Then select the number of pins in this case we have selected four virtual pins for each of the sensors we are using. Now when the project runs the values can be displayed on the app.

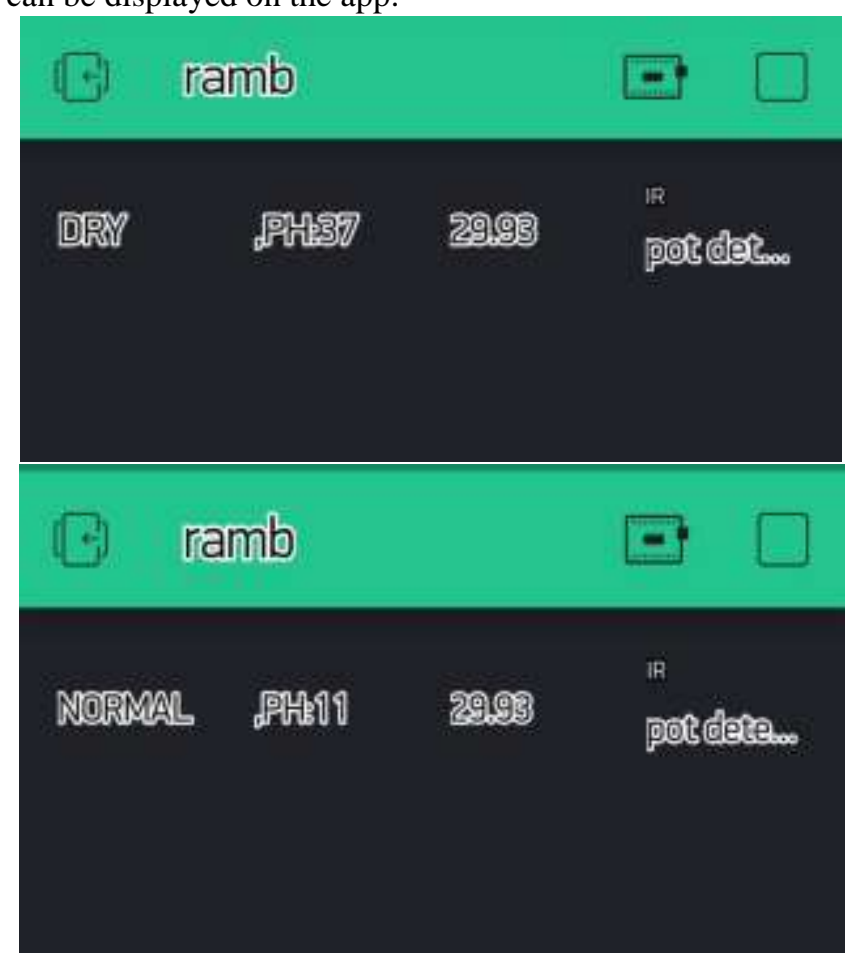

Figure 7: Values Obtained In Blynk App

\section{OUTCOMES \& RESULTS}

The health of the plant is monitored continuously with the help of different sensors. Water is supplied to the plants based on temperature, soil moisture, $\mathrm{pH}$ levels of the soil. With the help of image processing the condition of the plants like pigmentation, spots in the plant, chlorophyll levels are noticed. The values are displayed on the web page or an Android App. When the Pi-camera captures the images of the plant it compares with the RGB standards and according to that the robot selects the spray and sprays the pesticide.

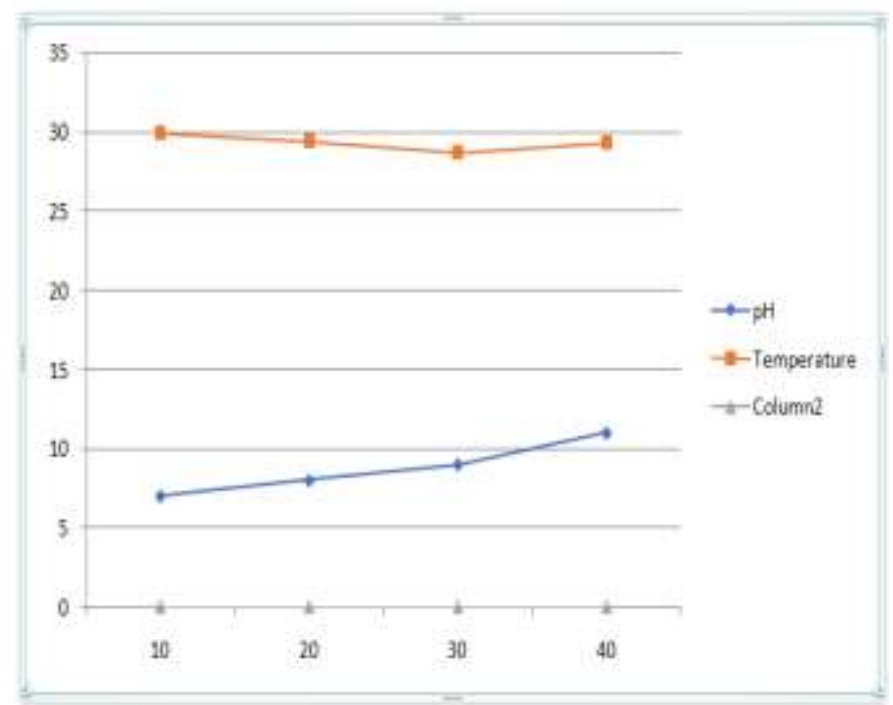

Fig. 8: Results obtained

\section{VII.APPLICATIONS}

This project finds its application in the field of research where immense care of plants is required. Hence people in the field of research of medicinal plants can make use of this project so that the plant's health is monitored at all the time even when they are away from the fields. This project can also be used in green houses and nurseries to prevent the disease occurrences in the plants. This project may also be used in the field of agriculture where large production for industries is involved.

\section{FUTURE SCOPE}

This project can be further developed by storing database in the system and by comparing the sensors values with the database values the results will be more accurate. Further, the image processing can be done using MATLAB simulation and the images can also be displayed during the time of operation of the robot. PLC can replace the relays as it has many more functions compared to a relay.

\section{REFERENCES}

1. Priyanka G. Shinde, Ajay K. Shinde, Ajinkya A. Shinde, Borate S. P. "Plant Disease Detection Using Raspberry PI By K-means Clustering Algorithm". International Journal of Electrical, Electronics and Computer Systems (IJEECS), 2017. 
3. Prof.Meenakshi Saron, Ajinkya Borse, Rohan Parsekar, Vinit Harsora , Pratik Shirsekar, "Autonomous Plant Health Indication System Using Image Processing In MATLAB", IOSR Journal of Engineering (IOSRJEN) , ISSN (e): 22503021, ISSN (p): 2278-8719 Volume 12, PP 56-58.

4. Ashutosh Gupta, Varun Krishna, Saarthak Gupta and Jitesh Aggarwal. "Android based Solar Powered Automatic Irrigation System". Indian Journal of Science and Technology, Vol 9(47), DOI: 10.17485/ijst/2016/v9i47/101713, December 2016.

5. Kavita Bhole, Dimple Chaudhari. "Solar Powered Sensor Base Irrigation System".International Research Journal of Engineering and Technology (IRJET), Feb-2016.

6. J.P. Reges, E.J. Braga, E.J. Braga, A.R. de Alexandria, "Inserting Photovoltaic Solar Energy to an Automated Irrigation System", International Journal of Computer Applications (0975 - 8887) Volume 134 - No.1, January 2016.

7. P Srinivas, K Vijaya Lakshmi, "Solar Energy Harvester for Wireless Sensor Networks", International Journal o Innovative Research in Electrical, Electronics, Instrumentation and Control Engineering, ISO 3297:2007 Certified, Vol. 5, Issue 6, June 2017.

8. N. Pughazendi, M. Muthukumaravel, M. Sushil, V. Sai Manohar, "Wireless Solar Powered Automatic Drip Irrigation System", International Journal of Pure and Applied Mathematics, Volume 118 No. 22 2018, 1133-1143, ISSN: 1314-3395 (on-line version), url: http://acadpubl.eu/hub Special Issue.

9. Md. Tanvir Arafat Khan, S.M. Shahrear Tanzil, Rifat Rahman, S M Shafiul Alam, "Design and Construction of an Automatic Solar Tracking System", 6th International Conference on Electrical and Computer Engineering ICECE 2010, 18-20 December 2010, Dhaka, Bangladesh.

10. Ghulam Mustafa Choudhary, Vikrant Gulati, "Advance in Image Processing for Detection of Plant Diseases", International Journal of Advanced Research in Computer Science and Softer Engineering RReseach Paper, Volume 5, Issue 7, July 2015, Available Online at: www.ijarcse.com.

11. Neha D. Kherade, Jyoti Kute, Pooja Pashte, Pranita Marye, Prof. DR. Saurabh Mehta, "Autonomous Farming Robot with Plant Health Indication", International Journal of Advance Engineering and Research Development Volume 4, Issue 3, March -2017.

12. Suman, Manjari Sharma, Srishti Tyagi, "Solar Powered Auto Irrigation System using GSM Module", GRD JournalsGlobal Research and Development Journal for Engineering, Volume 2, Issue 6, May 2017, ISSN: 2455-5703.

13. Jia Uddin, S M Taslim Reza, Qader Newaz, Jamal Uddin, "Touhidul Islam, and Jong-Myon Kim, Automated Irrigation System Using Solar Power", $20127^{\text {th }}$ International Conference on Electrical and compute Engineering, 20-22 December, 2012, Dhaka, Bangladesh. 